\title{
The 2015 Qualitative Election Study of Britain
} Social and Political Science

\author{
Kristi Winters \\ GESIS, Cologne, Germany \\ kristi.winters@gesis.org \\ Edzia Carvalho \\ University of Dundee, U K \\ e.carvalho@dundee.ac.uk
}

\author{
Thom Oliver \\ University of the West of England, Bristol, uk \\ thom.oliver@uwe.ac.uk
}

\begin{abstract}
The Qualitative Election Study of Britain (QESB) is the first (and only) qualitative longitudinal dataset to investigate political attitudes and voting behaviour over multiple elections and referendums in the United Kingdom. During the 2015 U K general election over 90 voters participated in 23 focus groups across England, Scotland, and Wales before and after polling day. These participants represented a range of political party supporters and independent voters, age groups, and economic backgrounds. They discussed a range of political issues including their vote choice in the election, their impressions of the major party leaders, why they would consider voting (or never voting) for a political party, and their expectations for the country moving forward. Special focus groups were also held around the three leaders' debates. The 2015 QESB also brought back participants who had participated in the 2010 QESB focus groups and the 2014 Scottish referendum focus groups. The 2015 QESB has created a unique panel of participants whose political opinions can be tracked across multiple elections. The project also includes questions that were asked in prior election focus groups and has replicated, with some modifications, the research design of the previous wave of the study.
\end{abstract}

(C) KRISTI WINTERS, EDZIA CARVALHO \& THOM OLIVER, 2017 | DOI:10.1163/24523666-01000007

This is an open access article distributed under the terms of the prevailing CC-BY license at the time of publication. 


\section{Keywords}

British elections - data replication - focus groups - election studies - qualitative research - qualitative data

- $\quad$ Related data set "Qualitative Election Study of Britain, 2015" with Do I http://dx.doi.org/10.5255/UKDA-SN-8117-1 in repository “U K Data Service”.

\section{Introduction}

In 2015, Britons voted after experiencing their first full term coalition government since 1945. This article provides background and technical information in support of the 2015 Qualitative Election Study of Britain (QESB), which collected qualitative data on Britons' political opinions and voting behaviour during the 2015 general election.

Survey data and inferential statistics have been used by British Election Study (BES) teams since 1964 to explain party choice, turnout, and election outcomes, and to analyse trends in voting behaviour (see Denver, 2005 for a brief summary of the BES). These surveys predetermine the wording of response options and only rarely are people asked to give an answer in their own words. Quantitative research seeks to identify, isolate, and measure causal processes in political behaviour, making it ideal for investigating people's understanding or perceptions of meaning, relationships, states of mind, and social processes. Qualitative investigations give participants the opportunity to express and justify their decisions in their own words, often revealing a rich and complex tapestry of motives, influences, and determinants that cannot be captured through set responses. However, there are only a handful of academic qualitative publications on British electoral behaviour (Bartle, 2003; Campbell \& Winters, 2008; White et al., 1999; Winters \& Campbell, 2007). A main aim of the QESB is to generate qualitative longitudinal data for social science analysis. It is the first (and only) qualitative dataset to investigate political attitudes and

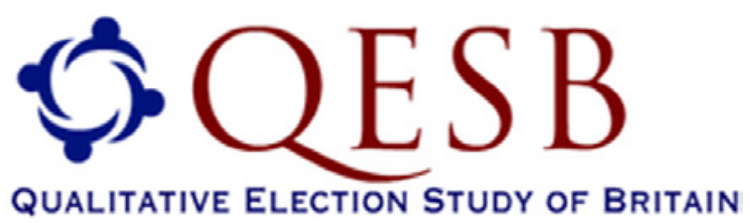

FIGURE 1 The QESB logo. 
voting behaviour over multiple general elections (Carvalho \& Winters, 2013, 2015; Winters, 2010; Winters \& Carvalho, 2013, 2014). This research fills a lacuna in extant electoral research by providing information from potential voters in their own words and using their own narratives rather than selecting a predetermined response option.

\section{Research Aim}

The 2015 QESB represents the third wave of focus groups conducted across Britain before and after UK elections. Previous rounds of the QESB were held during the 2010 UK general election and after the 2014 Scottish independence referendum. These follow on from a 2005 study conducted by Rosie Campbell and Kristi Winters during the 2005 UK general election campaign. Since its inception, the QESB has sought to ensure that each wave of the study replicates the data collection procedures of previous waves while updating the process to reflect concerns specific to the election campaign and include methodological innovations that improve data quality. The term 'replication' is contested and remains the subject of confusion and controversy in the social sciences. There is particular concern about the standards that replicated or replicable research need to adhere to and the extent to which context, reflexivity, and investigator bias are taken into account when evaluating replicable qualitative research (inter alia, Herrnson, 1995; Lucas et al., 2013). The QESB has been designed to meet the standards set out by Lincoln and Guba in a series of works (inter alia, Guba, 1981; Guba \& Lincoln, 1994) and which have been discussed elsewhere in relation to the QЕSB (see Winters et al., 2016).

\section{Replicating Qualitative Research}

The core interview schedule for the QESB 2015 was developed in consultation with the project's Advisory Board and with input from the QESB project partner, the UK Electoral Commission. The 2015 interview schedule replicated 2005 focus groups and QESB 2010 study questions to preserve the series (Winters, 2010; Winters \& Campbell, 2008). Some questions were replicated to connect the 2015 data to the 2010 QESB and the 2014 Scottish referendum datasets and to maintain the longitudinal series. The repeat inclusion of these questions allows a researcher the opportunity to conduct analyses on multiple levels: on how panel participants, participants with specific demographic or partisan characteristics, or in particular nations responded to the same questions over 
multiple waves. To maintain the responsiveness of data collection to events unfolding during the campaign, question space was included on the focus group schedule (equivalent to one long or two short questions), the wording for which was determined nearer the election. Below are the pre- and postelection focus group question themes. Those with a hash (\#) indicate questions asked in the 2005 study, questions marked with an asterisk $\left(^{*}\right)$ were replicated from the 2010 QESB, and those with a plus (+) were added from the 2014 Scottish referendum series. This list of themes does not include follow-up questions that were asked by focus group moderators to delve deeper into participants' responses.

\section{1. $\quad$ Pre-Election Topics}

(1) Icebreaker question: Theme song for the leaders

(2) Media and social media consumption ${ }^{+}$

(3) Impressions of the campaign*+

(4) Evaluating the party leaders ${ }^{\#+*}$ (seven leaders)

(5) Which leader would you want and not want to be stuck in a lift with?

(6) Which parties could you see yourself voting for?

(7) What things do you consider when voting? * *

(8) Opinions of leaders' debates*

(9) Voter registration experiences

(10) Predict the outcome of the election

3.2. Additional Topics Only Asked in Pre-Election Leaders' Debates Focus Groups

(11) Expectations of the debate (in the session before the debate)*

(12) Evaluations of leader performance (in the session after the debate)*

(13) Evaluations of the debate format and the moderator performance (in the session after the debate)*

\subsection{Post-Election Topics}

(1) Story of your vote choice and experience of Election Day.+*

(2) Reactions to the election outcome. ${ }^{+*}$

(3) Do the Conservatives have a mandate for their manifesto agenda?

(4) Are there any policies or politics that you will be paying attention in the weeks and months ahead?

(5) Would you say the election itself was fair and well run? 
(6) Will the 2015 election outcome influence your vote in the 2016 devolved legislature elections?

In addition to the questions and themes, the research design and data collection processes for the 2015 QESB were also replicated from the previous waves of the study. These are discussed in the next section.

\section{Methods}

The 2015 QESB conducted 14 pre-election and 9 post-election focus groups to investigate what Britons thought about the campaign and the election result. Focus groups were conducted in April and May 2015. One-hundred percent of the people who participated in the post-election focus groups were participants from the pre-election focus groups (i.e., no top-up recruitment was required). Participants were recruited by re-inviting focus group participants from the 2005 study, the 2010 QESB, and the 2014 Scottish referendum focus groups. By doing this, the 2015 QESB has created a unique panel of participants whose political opinions can be tracked across multiple elections (see Figure 2). Social media (primarily Twitter), local media in Dundee (radio and newspaper), and e-mail recruitment using university email lists were used to collect a pool of participants for sampling.

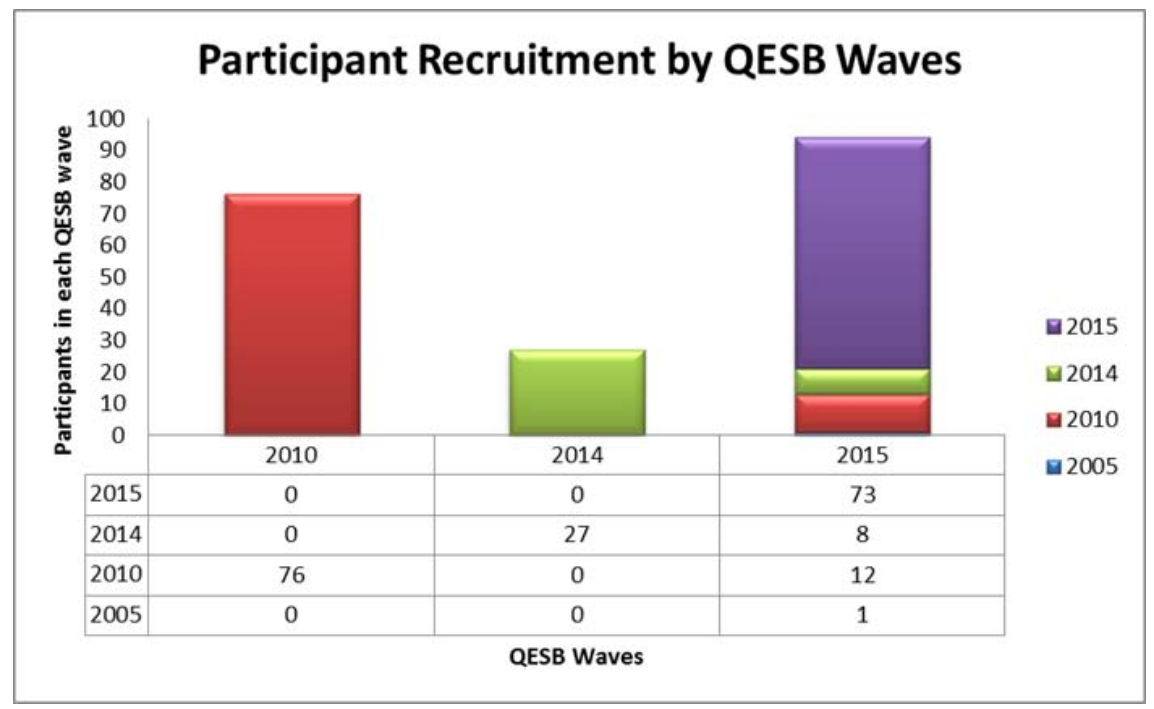

FIGURE 2 Participants across QESB waves. 
The 2015 wave also used the same sampling frame as in the 2010 study. Multiple sampling layers at macro, meso, and micro levels were included to reflect the needs of the research. These layers determined where and when focus groups were held and which individuals were chosen to participate in the groups. Time (pre- and post-election) was a macro-level layer. Meso-level layers took into account the nations (England, Scotland, and Wales), geography (North vs. South), constituency-level dynamics (safe seats, and 2-way and 3-way marginal seats), and constituency-level support (Labour, Scottish National Party, Conservatives, Plaid Cymru, and Liberal Democrats). The meso-layer determined the locations for the focus groups. Given the resource limitations, these locations were determined as Dundee and Glasgow in Scotland, Cardiff in Wales, and Birmingham, Colchester, and Clacton in England. The micro-level layer contained individual characteristics including demographics, economic background, and partisanship. Potential participants were asked to complete a pre-event questionnaire that included questions on participants' demographic information, party support, and current vote preference. Participants were selected to achieve an overall pool that broadly reflected the British population (see Figures 3-6).

We sought ethical approval from the appropriate department of our host university (University of Dundee, UK). Our application included plans for participant anonymity, confidentiality, data management, and data protection. These ethical compliance plans as well as participant information brochures and copies of the consent forms have been deposited alongside the data.

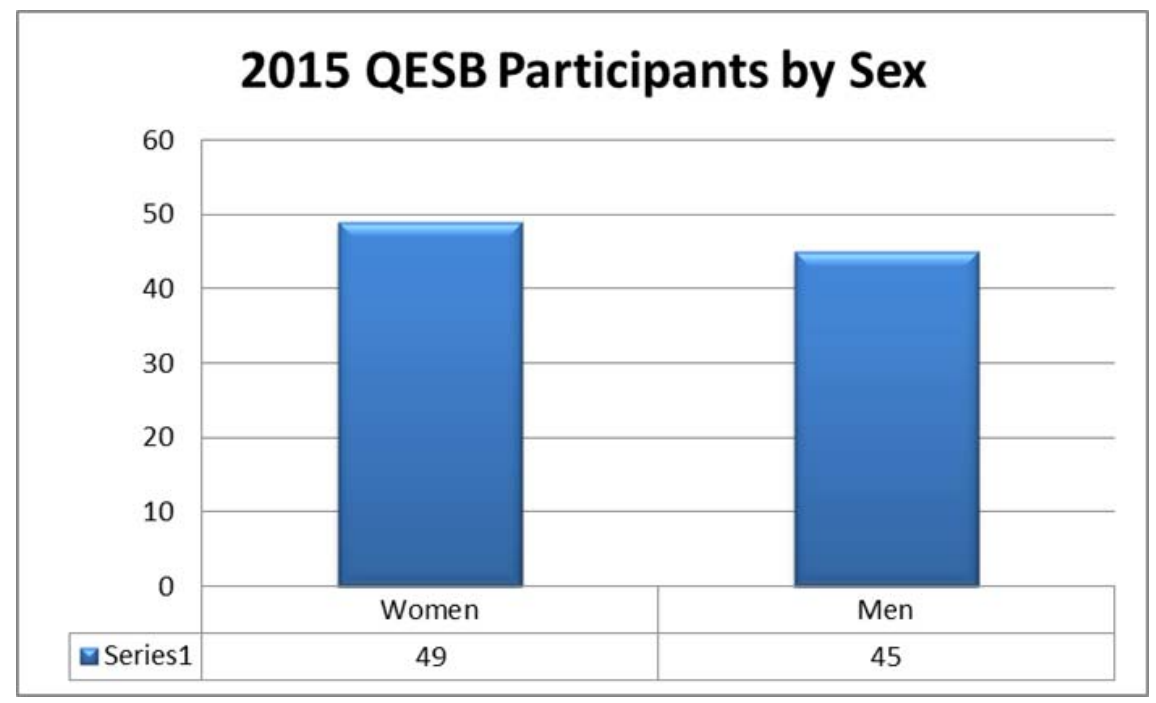




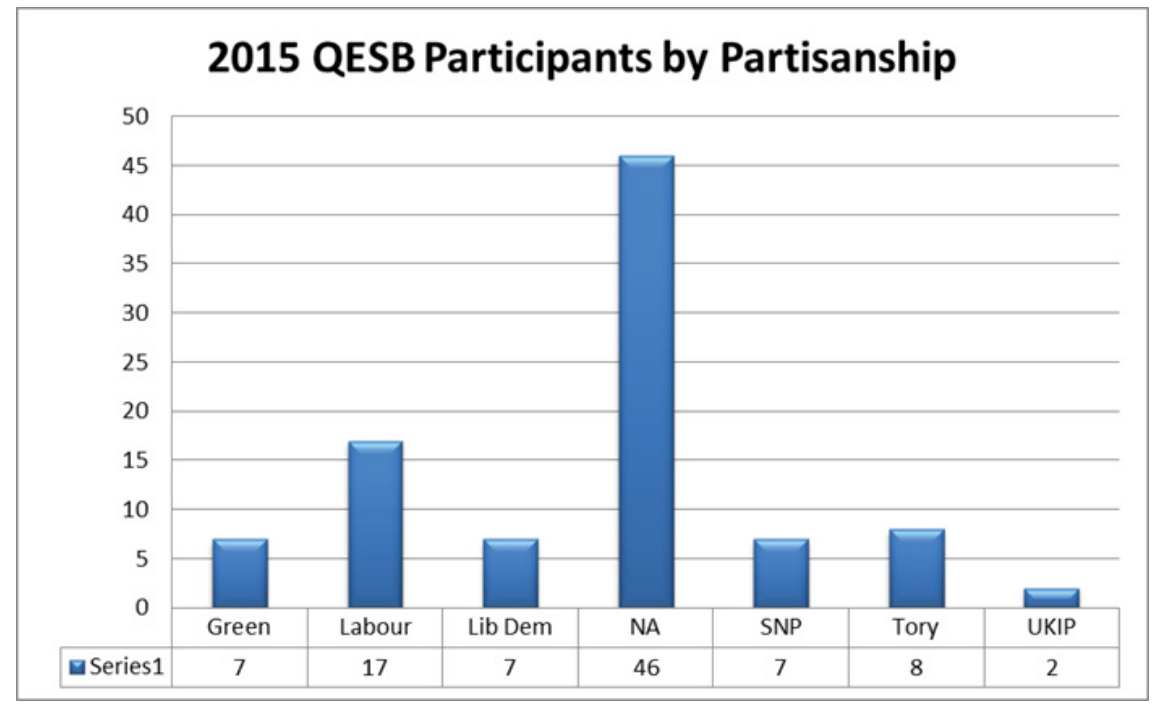

FIGURE 4

2015 QESB participants by partisanship. ' $N A$ ' = not applicable, refers to those who do not consider themselves partisan.

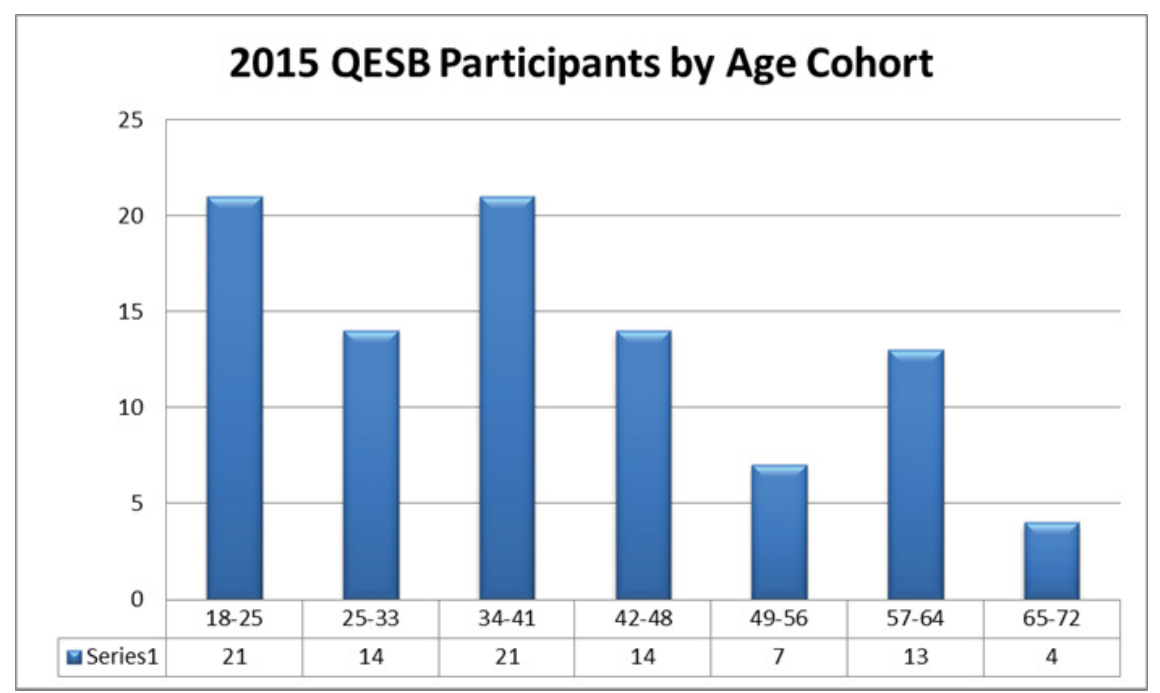

FIGURE $5 \quad 2015$ QESB participants by age cohort. 


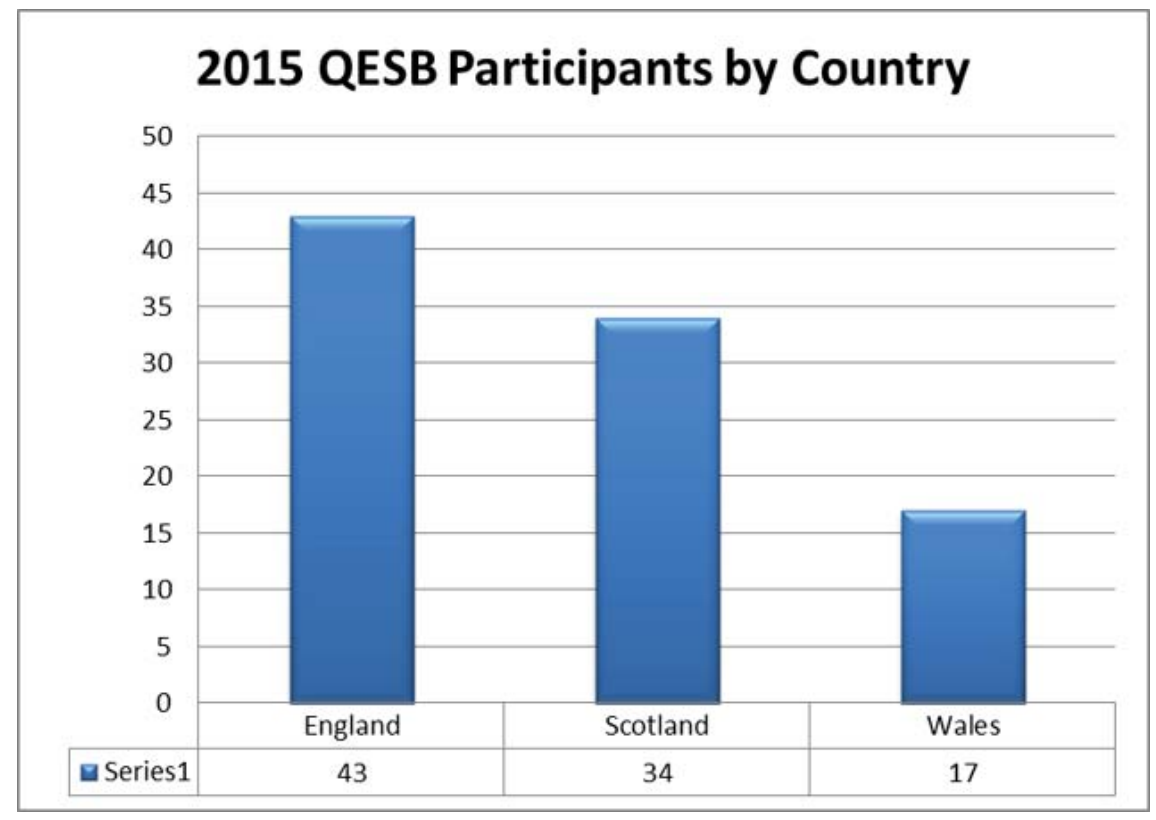

FIGURE 6

2015 QESB participants by country.

The consent forms signed by participants have been deposited with the UKDA to ensure preservation of the data. Researchers will not have access to these signed forms.

Participants were offered a small incentive $\left(£_{30}-£_{40}\right)$ to increase participation rates. Each focus group lasted for 90 minutes and took place in the evening and on weekends to allow full-time workers the option to participate. Participants received written information on informed consent and the procedures used in the project to ensure their anonymity (see Figure 7 ). These details and forms were reviewed verbally at the start of each focus group. Part of the application for ethical approval from our university included plans for participant anonymity, confidentiality, data management, and data protection. These ethical compliance plans as well as participant information brochures and a copy of the consent form has been deposited alongside the data, as shown in Figure 7.

Special focus groups were also held around the three leaders' debates. The focus groups were held in Dundee, Cardiff, and Colchester. A pre-debate session of the focus group was held for 6 o minutes after which participants viewed the debate live. Participants were recorded while viewing the debate to capture verbal and non-verbal reactions in real time. In the 2015 study, participants 


\section{CONSENT FORM}

Qualitative Election Study of Britain 2015

Dr Edzia Carvalho, School of Humanities, University of Dundee \&

Dr Kristi Winters, GESIS, Germany

(Project funded by the British Academy and the Leverhulme Trust)

- I have read and understood the project information brochure that was sent to me by the researchers.

- I have been given the opportunity to ask questions about the project. I also understand I may ask further questions about this research at any time.

- I agree to take part in the project. Taking part in the project will include being interviewed and recorded (video and audio).

- I understand that my taking part is voluntary; I $c a n$ withdraw from participating at any time and I will not be asked any questions about why I no longer want to take part. The focus group discussions I bave participated in of iaterview I have given until my withdrawal may still be used.

- I agree for the data I provided to be archived at the UK Data Archive and I understand that other researchers will bave access to this data only if they agree to presenve my anonymity and confidentiality terms as specified in this form.

- If I am being interviewed by the researchers, I do so acknowledging that my submission is voluntary. I can ask the researchers to withhold use of my submission at any time before it is submitted to the UK Data Archive for publication.

- I understand that my words may be quoted in publications, reports, web pages, and other research outputs but my name of other identifying details will not be used.

- I hereby assign the copyright of my contribution to Drs Carvalho and Winters, so that my words may be quoted in publications, reports, web pages, and other research outputs.

- I would / would not (delete as appropriate) like to be notified of any poblications which are produced from this research. I would like to be notified of this by e-mail / text / phone call (delete as appropriate) and have provided the relevant contact information to Drs Carvalbo and Winters.

FIGURE 7 Page 1 of the 2015 QESB Consent Form.

were also given sheets for each leader with instructions to note down their responses to what the leaders were saying and doing and score leaders' performance (see Figure 8). After the debate, and a comfort break, participants were led into an evaluation of the debate and their impressions of how the leaders did.

5. Data

- QESB 2015 - DOI:10.5255/UKDA-SN-8117-1

- Temporal coverage: 2015 


\section{vigel Farage}

The UK Independence Party

\section{Brass Eye!}

Topic: Sefucit

Grade: $F$.

Comments: Slags off foreign aid, EUt scots in Tininute. Keeps blaming

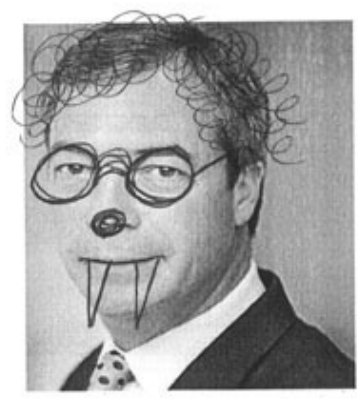
Shouty.

Topic: NHS.

Grade: F.

Comments: Funded by the money we curreatly qive to nasty foreigness + scottish people.

Tosspot.

Topic: /mmigration

Grade: $F$

comments: Its the communist foreignens thats' the problem ....

Overbearing one-trick pony.

Shouty. Makes faces like a frog swallowing

a big slug. Patronizing.

FIGURE 8 A participant's comments while watching a leaders' debate. 


\section{1. $\quad 2015$ Study Data}

The focus groups were recorded with digital and audio equipment and transcribed. Two audio and video recorders were used per focus group to ensure backups of the recordings. Audio was recorded in .wma and .mp3 formats and video in .mp3 and .mp4 formats. Transcription was outsourced to a professional transcriber who converted audible words into text by listening to the audio recordings. The transcriber did not identify participants other than recording their sex and distinguishing between participants and moderators. The transcriber also did not record any audible non-verbal communication. On receiving these raw versions of the 23 transcriptions, the participants in the transcripts were identified first by their original names. They were then anonymized and all identifying or confidential information was removed and each of the 94 participants was given a unique alias. Non-verbal responses audible on audio recordings were also added to the transcripts.

The transcripts are available as Word documents in .docx and .docx versions pre-prepared for use in Nvivo (see Figure 9). The pre- and post-election questionnaires given to the participants are also available, as are the responses to the questionnaires, in SPSs, Stata, and Excel formats. Also available are the audio and video recordings of the focus groups in .wma, .mp3, and .mp4 formats, and the ethical approval forms. Participants' hand written responses on the questionnaire sheets include not just the words written by participants but doodles and scribbles to emphasise or express their opinions. These sheets are data artefacts in themselves as they are useful to add context to participants' words (see Figure 8). These sheets will be deposited with the UKDA subsequently. Any data that would consist of participant identifiers - signed consent forms, audio and video recordings, and hand written responses with participant names on the sheets - will be restricted to researchers who sign ethical agreements with the UKDA for access to these data and agree to keep participant identities anonymous when using these data.

The transcript data included verbal and non-verbal responses to questions asked in the focus groups (see section on Research Aim). In the pre-election focus groups, participants were asked to introduce themselves, often by thinking about a response to an ice breaker question or by discussing their impressions of the campaign. Participants were also probed for the kinds of media they consumed, often by asking them to raise their hands if they read newspapers in print or online, followed the news on Facebook, Twitter, or other social media, or watched television. Participants were probed further for reasons why they chose to focus on some media over other formats.

The question on leader evaluations preceded a brainstorming session in which participants were asked to note down their first impressions of the main 


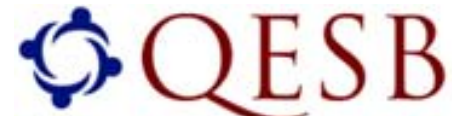

QUALITATIVE ELECTION STUDY OF BRITAIN

\title{
THE QUALITATIVE ELECTION STUDY OF BRITAIN 2015 Glasgow Pre-Election Leaders Debate Focus Group 2 conducted May $5^{\text {th }} 2015$
}

\author{
Transcribed Focus Groups Dataset \\ Version 1.0 \\ Date of release: 5 January 2015
}

\author{
Principal Investigator \\ Dr. Edzia Carvalho, University of Dundee \\ International Co-Investigator \\ Dr. Kristi Winters, GESIS, Cologne
}

Funded by

British Academy and Leverhulme Trust Small Grant SG142740

and supported by

Carnegie Corporation of New York, GESIS-Leibniz Institute (Cologne) and University of Dundee

FIGURE 9 Cover page of a QESB 2015 transcript.

party leaders whose pictures were printed on a sheet of paper (see Figure 10). Participants were asked to write down as many (or few) impressions that came to their mind on seeing these photographs and to note down which impressions had positive, negative, or neutral connotations to them. In the 2015 study, participants were asked to do this for all seven party leaders who were involved in at least one of the three leaders' debates. Subsequent to this written brainstorming, the focus group moderators led the participants in a discussion of 


\section{First Impressions}

Write the words or phrases which come to mind when you look at these photos. Afterwards consider which ones most impact your impression of this leader. Use the symbol $\uparrow$ to indicate if the word has a positive association, $\downarrow$ if negative, and * if neutral
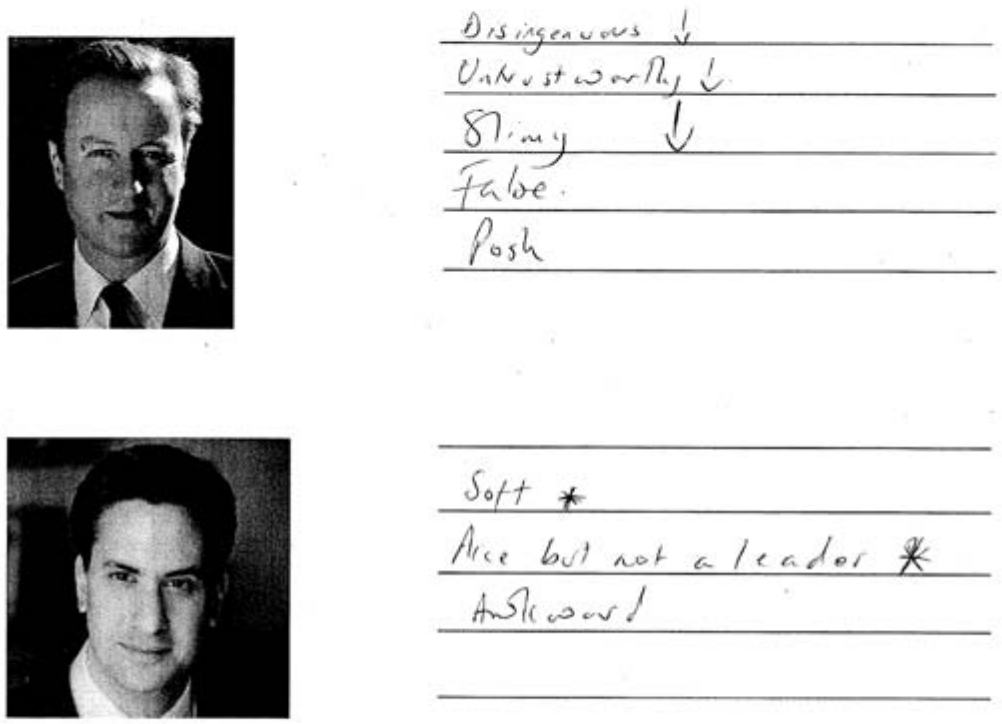

Soft *
Ace but not a leader *
Andenou!
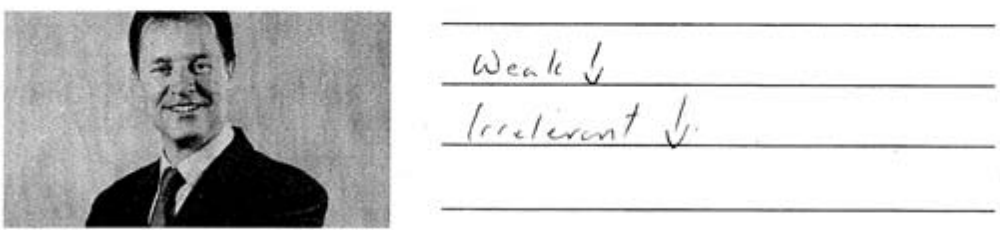

PTO

FIGURE 10 A participant's brainstorming on the UK party leaders.

their responses where participants got the opportunity of putting their initial responses into context and comparing them with the responses from other participants.

The question on vote choice narratives was also replicated from the 2010 QESB and the 2014 Scottish referendum studies. Participants were asked to 
relate, in the form of a story, their experience of Election Day, how they voted and why, how they found out and what they felt about the results. When asked to relate a story of their day, participants often do so in a way that is both unique to how and why they voted but also has elements common with other participants. These narratives may not be constructed in the same way by all participants. For example, not all participants will start by narrating when they got up on voting day and end with when they found out the results. Some participants may start by expressing a dilemma on how they were to vote. Others may start by recounting an incident that stayed in their memory. Yet, all participants will have elements of their story that they may share with others. For example, all participants will explain how and why they voted. Some participants may share the strength of their voting convictions, others the confusion on how to vote, still others may have faced a turning point in resolving this confusion. As previous analysis has shown (Carvalho and Winters, 2015), vote choice narratives can be used very well to examine the complexity of how individuals come to decide who to vote for and how they justify these reasons to themselves and to others.

Among the questions asked for the first time in the 2015 study, the question on 'Which parties could you see yourself voting for' is of particular interest to researchers on partisanship, vote choice, and political behaviour. First, participants were asked to circle all political parties (of the seven parties being represented in the leaders' debates) which they could see themselves voting for either at UK, national, or local levels. Participants then discussed why they chose or didn't choose certain parties and how the level of government affected their choice.

\subsection{Participant and Question Metadata}

For this project it is not sufficient to collect, transcribe, anonymise and publish the QESB 2015 data. To encourage reuse, a metadata structure for qualitative research which can be applied across national contexts has been created. This metadata structure will allow researchers to find transcript data based on study year, demographics, partisanship, constituency, pre- or post-election or research topic, among others; for instance, they could analyse post-election vote choice stories of men under 30 who were undecided pre-election but voted Conservative. The structure has been piloted on the 2015 data set. The new metadata structure will be applied to the QESB 2010 and to 2005 focus group data to produce a harmonised, longitudinal qualitative electoral dataset published for public use.

In addition to the focus group discussion data, each transcript includes the metadata on the participants and the questions asked (see Figures 11 and 12). 


$\begin{array}{llllllllllll}2015 & & \text { Special } & \text { Age } & & & & & & & 2015 \text { vote } & 2014 \text { Indyref } \\ \text { Alias } & \text { Sex } & \text { Category } & \text { group } & \text { Supporter } & \text { Party } & \text { Strength } & \text { Pre Group } & \text { Post Group } & \text { Constituency } & \text { preference } & \\ \text { Zachary } & \text { M } & \text { N } & 34-41 & \text { N } & \text { NA } & \text { NA } & \text { Glasgow 2 } & \text { Glasgow } & \text { Glasgow South } & \text { Y, and party } & \text { Yes } \\ \text { Luke } & \text { M } & \text { N } & 42-48 & \text { N } & \text { NA } & \text { NA } & \text { Glasgow 2 } & \text { No } & \text { Renfrewshire East } & \text { Y, and party } & \text { Yes } \\ \text { Thomas } & \text { M } & \text { N } & 18-25 & \text { Y } & \text { SNP } & 3 & \text { Glasgow 2 } & \text { Glasgow } & \text { Ayr, Carrick and Cumnock } & \text { Y, and party } & \text { Yes } \\ \text { Una } & \text { F } & \text { Student } & 34-41 & \text { Y } & \text { SNP } & 4 & \text { Glasgow 2 } & \text { Glasgow } & \text { Glasgow North } & \text { Y, and party } & \text { Yes }\end{array}$

FIGURE 11 Summary of metadata from a QESB 2015 transcript.

\section{Contents}

CAMPAIGN IMPRESSIONS.........................................................................................................................8

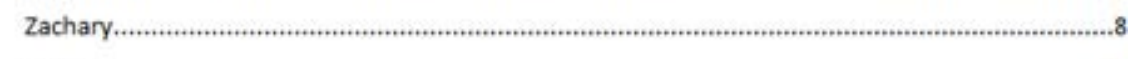

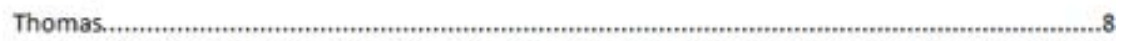

Thomas

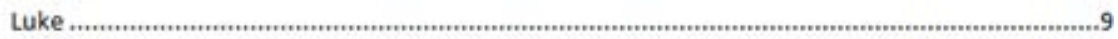

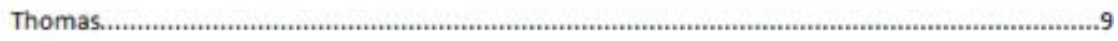

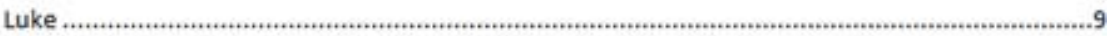

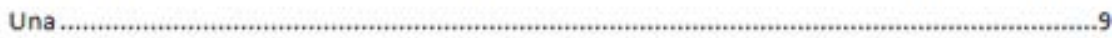

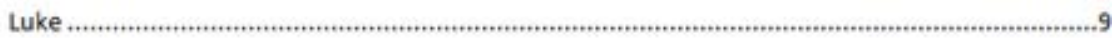

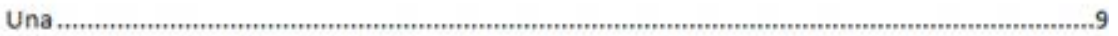

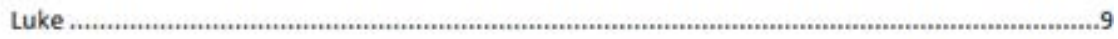

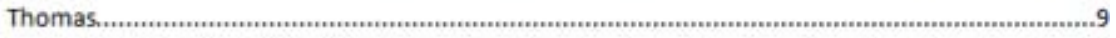

Luke ........................................................................................................................................................9

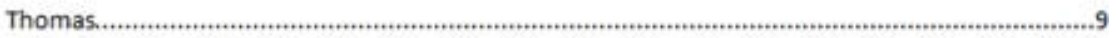

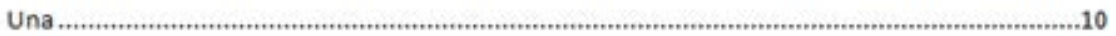

MEDIA CONSUMPTON...........,

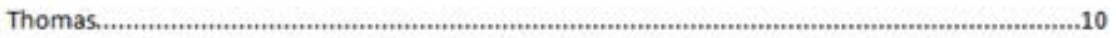

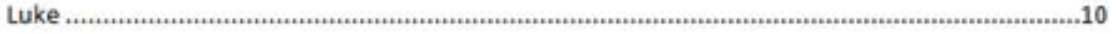

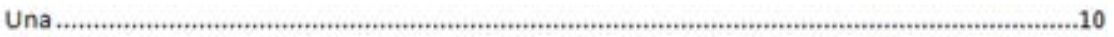

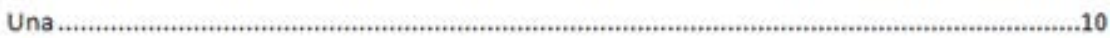

Una ........,

Thomas.

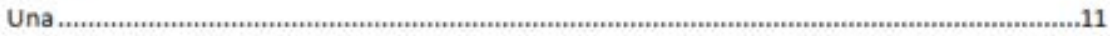

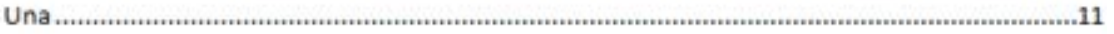

Luke .........................................................................................................................................11

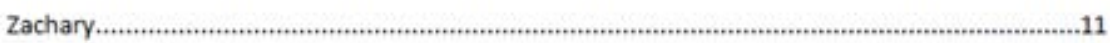

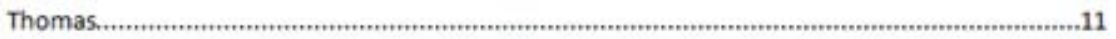

PARTY LEADER HANDOUT..., ,

FIGURE 12 Hyperlinked participant IDs from a QESB 2015 transcript. 
Each transcript contains a table with the following information for each participant: 2015 Alias (name), Sex (male or female), Special Category (student, stay at home parent, unemployed or retired), Age group (by cohorts), Supporter (yes, supporter of a party or not), Party Strength (1 low party strength to 5 high party strength), Pre Group (name of the pre-election focus group location), Post Group (name of the pre-election focus group location), Constituency (name of the constituency they vote in).

Each transcript also contains a table of contents with two types of hyperlinks: links based on the question and links to each participant's comments. The inclusion of these hyperlinks should make it easier to narrow down specific answers in order to compare data or, alternatively, to follow the comments of a particular set of people based on a common characteristic (location, age, sex, partisan identification, etc.).

A master list with each location, date, participants and questions asked will be made available and will be accompanied by a similar list of the metadata on questions and participants from the $2010 \mathrm{QESB}$, facilitating cross-election analysis.

\subsection{Access Information}

Copyright of the transcripts and documentation belongs to Dr. Edzia Carvalho and Dr. Kristi Winters. The data are available under safeguarded access and documentation is available to download for free.

\section{Acknowledgements}

Version 1.0 of the data was funded by British Academy and Leverhulme Small Grant SG142740 and supported by GESIS, Carnegie Corporation, and University of Dundee.

\section{QESB Media}

QESB website:

QESB YouTube channel:

www.qesb.info www.youtube.com/channel/UCIfH-jfDQ BXN2rugmJwvidQ

How to use the QESB transcripts: https://youtu.be/xc_wySWs8wc

Facebook:

Twitter: /qualesb2015 @qualesb 


\section{References}

Bartle, J. (2003). Measuring party identification: An exploratory study with focus groups. Electoral Studies, 22(2), 217-237.

Campbell, R. \& Winters, K. (2008). Understanding men's and women's political interests: Evidence from a study of gendered political attitudes. Journal of Elections, Public Opinion and Parties, 18(1), 53-74.

Carvalho, E. \& Winters, K. (2014). The grounded theory method: Popular perceptions of party leaders during the 2010 British General Election. London: SAGE Publications. doi:10.4135/978144627305013510259.

Carvalho, E. \& Winters, K. (2015). 'I went with what I always do...': A qualitative analysis of the effect of 'Cleggmania' and vote choice in the 2010 British General Election. Parliamentary Affairs, 68(2), 423-446.

Denver, D. (2005). 'Valence politics': How Britain votes now. British Journal of Politics and International Relations, 7, 292-299.

Guba, E. (1981). ERIC/ECTJ annual review paper: Criteria for assessing the trustworthiness of naturalistic inquiries. Educational Communication and Technology, 29(2), 75-91.

Guba, E. \& Lincoln, Y. (1994). Competing paradigms in qualitative research. In N. Denzin \& Y. Lincoln (eds.) Handbook of qualitative research (pp. 105-17). Thousand Oaks: Sage.

Herrnson, P. (1995). Replication, verification, secondary analysis, and data collection in political science'. Ps: Political Science and Politics, 28(3), 452-455.

Lucas, J., Morrell, K. \& Posard, M.. (2013). Considerations on the "replication problem" in Sociology. The American Sociologist, 44, 217-232.

White, C., Ritchie, J., \& Devine, F. (1999). Voter volatility: A qualitative study of voting behaviour at the 1997 General Election. London, : Social and Community Planning Research.

Winters, K. (2010). Public version: first, second and third Leaders Debates transcripts (Qualitative Election Study of Britain). Retrieved from http://qesb.info.

Winters, K. \& Campbell, R. (2007). Hearts or minds? Men, women and candidate evaluations in the 2005 General Election. In D. Wring, J. Green, \& R. Mortimore (eds.), Political Communication: The General Election Campaign of 2005 (pp. 184-202). Basingstoke, U K: Palgrave Macmillan.

Winters, K. \& Carvalho, E. (2013). 2010 British General Election leader evaluations: A case study using focus group data. The Qualitative Report, 18(45), 1-21.

Winters, K. \& Carvalho, E. (2014). The qualitative election study of Britain: Qualitative research using focus groups. London: SAGE Publications Ltd. doi:10.4135/978144627 305013509945 . 
Winters, K, Carvalho, E. \& Oliver, T. (2016). 'Designing qualitative research for replication and secondary analysis: A case study using the Qualitative Election Study of Britain', From Transparency to Replication in Qualitative Inference: Guidelines and Tools research workshop. University of Essex, Colchester, 23-24 May 2016. 